\title{
ERRADICAÇÃO DE ESCLERÓDIOS DE Sclerotium rolfsii EM SUBSTRATOS TRATADOS EM COLETORES SOLARES, EM CAMPOS DOS GOYTACAZES-RJ ${ }^{1}$
}

\author{
MARLON VAGNER VALENTIM MARTINS'2, SILVALDO FELIPE DA SILVEIRA³, ALMY JUNIOR CORDEIRO DE \\ CARVALHO $^{3}$, ELIAS FERNANDES DE SOUZA ${ }^{4}$
}

\begin{abstract}
RESUMO - Na produção de mudas de fruteiras em geral, o uso de solo na composição de substratos ainda é a prática mais econômica e utilizada pelos agricultores, embora haja o risco deste conter inóculos de fitopatógenos. Visando uma alternativa à esterilização química com brometo de metila, neste trabalho avaliou-se a eficiência de coletores solares para a desinfestação de substratos contendo solo, na erradicação de escleródios de $S$. rolfsii, em Campos dos Goytacazes-RJ. Os ensaios foram realizados nos dias: 6 e 25 de outubro e 13 de dezembro de 2000. Os escleródios recuperados dos substratos tratados nos coletores solares foram plaqueados em meio de cultura e submetidos à coloração em solução de cloreto de trifenil-tetrazólio (TCT). A coloração em TCT foi utilizada para comprovar se os escleródios não-germinados em meio de cultura foram realmente inativados pelo calor ou se houve indução de fungistase. No primeiro ensaio, em dia nublado, o máximo de temperatura alcançado no substrato foi de $45^{\circ} \mathrm{C}$ e a germinação dos escleródios foi nula e acompanhada de $100 \%$ de colonização por bactérias. Nas duas últimas datas de avaliação, em dias ensolarados, as temperaturas máximas alcançadas nos substratos variaram de $60 \mathrm{a} 80^{\circ} \mathrm{C}$ e os escleródios foram totalmente erradicados, em apenas um dia de tratamento. Nos três ensaios, os escleródios tratados não apresentaram atividade de desidrogenase, evidenciada pela falta de coloração avermelhada interna na presença de TCT, corroborando a inativação pelo calor. Conclui-se que mesmo em condições sub-ótimas para tratamento de substratos em coletores solares, a exposição prolongada a temperaturas elevadas foi suficientemente danosa aos escleródios do patógeno, tornando-os mais vulneráveis ao antagonismo microbiano. Os coletores solares foram eficientes na desinfestação dos substratos, visando o controle de $S$. rolfsii, nas condições avaliadas.
\end{abstract}

Termos para indexação: Tratamento de solo, solarização, estruturas de sobrevivência, substrato

\section{ERADICATION OF Sclerotium rolfsii SCLEROTIA IN SUBSTRATE TREATED IN SOLAR COLLECTOR DEVICES IN CAMPOS DOS GOYTACAZES-RJ}

\begin{abstract}
Although there is a risk of soil being contaminated with plant pathogen inocula its uses in the substrate composition is the most economical and useful practice for fruit propagation in general. In this work, looking for an alternative method besides the methyl bromide fumigation for soil sterilization the efficiency of solar collector devices for substrate disinfestations in the elimination of $S$. rolfsii sclerotia was evaluated. The assays were realized in three dates: October $6^{\text {th }}$ and $25^{\text {th }}$ and December $13^{\text {th }}$ of 2000 . For evaluation of the sclerotia viability the sclerotia recovered from the soil treated in solar collector were sown in culture medium and submitted to the tetrazolium staining test (tetrazolium triphenil-chloride). The tetrazolium coloration was used to confirm if non-germinated sclerotia were really heat inactivated or if there was fungistase induction. In the first assay during a cloudy day, the maximum temperature reached in the substrate was $45^{\circ} \mathrm{C}$ and the germination of sclerotia was null and accompanied by $100 \%$ of bacteria colonization. In the two last dates of evaluation during sunny days the maximum temperatures in the substrate varied from 60 to $80^{\circ} \mathrm{C}$ and the sclerotia were $100 \%$ eradicated with only one day-treatment. The staining test with TTC confirmed that non-germinated sclerotia were heat inactivated by the absence of red color due to the dehydrogenase activity inhibition (enzymatic denaturation). It was concluded that even under suboptimum conditions for substrate treatment in solar collector devices the long exposition to higher temperatures were enough to cause severe injuries in the pathogen sclerotia which became vulnerable to microbial antagonism. The solar collector devices were efficient for substrate disinfestations and for the control of $S$. rolfsii in the evaluated conditions.
\end{abstract}

Index terms: Sclerotium rolfsii, solarization, sclerotia, substrate

\section{INTRODUÇÃO}

A Podridão-de-Escleródio ou Murcha-de-Escleródio, causada por Sclerotium rolfsii Sacc., afeta uma vasta lista de espécies de plantas hospedeiras, incluindo dicotiledôneas e monocotiledôneas (Punja, 1985; Punja e Rahe, 1993). O patógeno pode causar tombamento em mudas e podridão do coleto e de raízes em plantas mais velhas, resultando em murcha, o que, na maioria das vezes, culmina com a morte da planta. $S$. rolfsii é amplamente distribuído pelas regiões tropicais e subtropicais do mundo, sendo favorecido por condições de temperaturas médias em torno de $27^{\circ} \mathrm{C}$ e alta umidade relativa do ar (Punja, 1985). Na ausência de hospedeiros, o fungo sobrevive no solo por meio de escleródios e pelo crescimento micelial saprofítico, e sua disseminação é feita, principalmente, pelo transporte de solo infestado. Áreas altamente infestadas por $S$. rolfsii podem ficar comprometidas para o cultivo de muitas culturas.

No Norte Fluminense, em área onde predominava o cultivo da cana-de-açúcar, a fruticultura vem se tornando muito importante no desenvolvimento regional, principalmente através do cultivo do maracuja- zeiro, goiabeira e abacaxizeiro. Com a franca expansão dessa atividade, muitos agricultores tendem a se tornar viveiristas ou produzir suas próprias mudas. A desinfestação do solo se torna muito importante uma vez que fungos como Rhizoctonia, Pythium e Phytophthora não possuem especificidade de hospedeiro, pois atacam desde de olerícolas até fruteiras. Estes fungos, por serem bastante agressivos, matam as plantas rapidamente através de enzimas e, conseqüentemente, diminuem a produção do viveiro (Bedendo, 1995). Daí surge a necessidade de mudas de qualidade, isenta de patógenos e também de plantas daninhas.

Com a proibição dos produtos fumigantes e esterilizantes, como o brometo de metila, que afeta a camada de ozônio (Albregts et al., 1996), a desinfetação de substratos para a produção de mudas pode ficar comprometida. Entretanto, devido às altas temperaturas verificadas na região do Norte Fluminense e pelas dificuldades no controle de doenças causadas por patógenos do solo, o uso da energia solar via solarização do solo pode ser uma alternativa promissora à esterilização química, no tratamento de solo e substratos para a produção de mudas em geral. Os patógenos de solo são controlados pelo aquecimento do solo em profundidade, por meio da cobertura do solo úmido com filme de polietileno

\footnotetext{
(Trabalho 020/2003). Recebido: 05/03/2003. Aceito para publicação: 18/08/2003. Apoio: FAPERJ

${ }^{1}$ Extraído da Tese de Mestrado do primeiro autor apresentada à Universidade Estadual do Norte Fluminense

${ }^{2}$ Eng. Agr., M.Sc., Doutorando, UENF/CCTA/LPP, Campos, RJ, CEP 28013-600. E-mail: varresai@uenf.br

${ }^{3}$ Eng. Agr., D.Sc., Professor Associado, UENF/CCTA, Campos, RJ, CEP 28013-600

${ }^{4}$ Eng. Ag ${ }^{\text {la }}$, D. Sc., Professor Associado, UENF/CCTA, Campos, RJ, CEP 28013-600
} 
transparente e exposição à radiação solar (Katan, 1980). Para o tratamento de substratos, a solarização pode ser efetuada em coletores solares (Ghini, 1991).

A desinfestação de substratos em coletores solares foi, inicialmente, testada na Embrapa Meio Ambiente, por R. Ghini e W. Bettiol (1991). O aparelho foi eficiente no controle de patógenos de solo, como S. rolfsii e Pythium aphanidermatum (Edson) Fitzpatrick (Ghini, 1991; Ghini e Bettiol, 1991; Ghini, 1993).

Este trabalho objetivou adaptar e testar coletores solares na erradicação de $S$. rolfsii em substratos para produção de mudas, no Norte Fluminense.

\section{MATERIAL E MÉTODOS}

O trabalho foi realizado na Universidade Estadual do Norte Fluminense, UENF, situada no município de Campos dos Goytacazes, Estado do Rio de Janeiro.

Produção de escleródios: Micélio de $S$. rolfsii do isolado Sr-1, originado de tomateiro doente, foi repicado do meio batata-dextrose ágar (BDA) para o meio de aveia (100 g de grãos de aveia, $50 \mathrm{~mL}$ de água destilada, $100 \mathrm{~mL}$ de meio de Ágar- $15 \mathrm{~g} \mathrm{dm}^{-3}$ ) e incubado a $27^{\circ} \mathrm{C}$, por 8 dias (Punja e Grogan, 1981). Após o crescimento do fungo, o manto micelial juntamente com o meio foi posto sobre camada de solo não esterilizado, em recipiente tipo-gerbo $\mathrm{x}^{\circledR}$ e incubado a $30^{\circ} \mathrm{C}$, por 14 dias (Punja e Grogan, 1981). Os escleródios foram recuperados do substrato por peneiramento úmido (Punja e Grogan, 1981). Após a recuperação em peneira de 65 meshes, os escleródios foram secos em papel-toalha e armazenados em tubos $(50 \mathrm{~mL})$ com $1 \mathrm{~g}$ de sílica-gel, a $22-27^{\circ} \mathrm{C}$, até a execução dos experimentos.

Construção dos coletores solares: Os coletores foram feitos em madeira Aparaju, com 1,52x0,90x0,24 m (Figura 1). Internamente alojou-se a um dos coletores seis tubos de irrigação de ferro-galvanizados, de 6" de diâmetro e $0,90 \mathrm{~m}$ de comprimento e num outro coletor utilizaram-se seis tubos de irrigação de alumínio, de 5" de diâmetro e $0,90 \mathrm{~m}$ de comprimento. A caixa coletora foi pintada com piche e os tubos com tinta preta fosca automotiva. Na parte superior, foi colocado um filme de polietileno transparente de 50 ìm de espessura. $\mathrm{O}$ ângulo de inclinação do coletor foi de $33^{\circ}$ (Ghini e Bettiol, 1991).

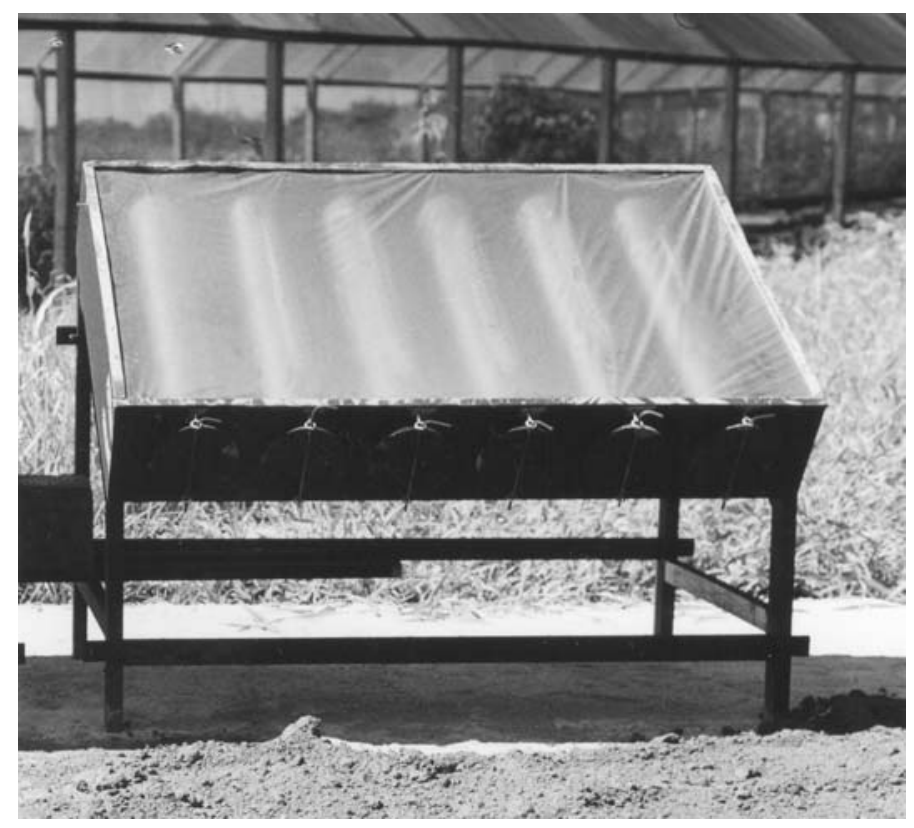

FIGURA 1 - Protótipo de coletor solar, com dimensões de 1,52 x 0,90 x $0,24 \mathrm{~m}$, de baixo custo produzido na Universidade Estadual do Norte Fluminense.
Erradicação dos escleródios nos coletores solares: Efetuaramse três ensaios nas datas de 6 e 25/10 e 13/12 de 2000. Testaram-se dois substratos. O primeiro substrato testado nos dois primeiros ensaios foi uma mistura de duas partes de solo (Argissolo Amarelo) com uma parte de areia. O segundo substrato testado no terceiro ensaio foi terra de lavagem da cana-de-açúcar. Para os primeiros e segundos ensaios foram introduzidas, em três pontos do tubo, três pequenas bolsas de nylon (10 $\mathrm{mL}$ ) com $5 \mathrm{~g}$ do substrato infestado com 45 escleródios. Para o terceiro ensaio, as bolsas de nylon foram colocadas na posição mediana dos tubos 2, 3, 4 e 5. Os substratos foram umedecidos de acordo com o valor do potencial hídrico (-1/3 bar), referente à capacidade de campo. Para os ensaios, os coletores foram abastecidos ao entardecer anterior ao dia de tratamento. Como testemunha, quatro repetições de 45 escleródios misturados aos substratos foram colocados em cápsulas de alumínio de 100 $\mathrm{mL}$ e mantidos em laboratório durante o mesmo período dos tratamentos.

Monitorou-se o aquecimento do substrato no período de 8 às $17 \mathrm{~h}$, por meio de sensores de solo (termopar). As temperaturas foram registradas a intervalos de $25 \mathrm{~min}$, em coletor de dados (Watch Dog Model 425 Spectrum Tecnology ${ }^{\circledR}$ ). Nos primeiro e segundo ensaios, foram colocados três sensores dentro de um dos tubos centrais nos 2 coletores, nas posições superior, mediana e inferior de cada tubo. No terceiro ensaio, colocou-se um sensor na posição mediana dos três tubos centrais. A radiação solar global $\left(\mathrm{W} \mathrm{m}^{-2}\right)$ e a temperatura do ar externo foram obtidas pela Estação Climatológica da UENF (Estação Automática THIES CLIMA ${ }^{\circledR}$ ).

Teste de Trifenil Cloreto de Tetrazólio: $\mathrm{O}$ teste de Trifenil Cloreto de Tetrazólio (TCT), utilizado em análise do vigor de sementes, foi utilizado em paralelo com o teste de germinação em meio de cultura, com objetivo de certificar a viabilidade dos escleródios de $S$. rolfsii tratados nos coletores solares. Para isso, utilizou-se uma solução do sal de TCT 0,5\% em água destilada, pH 6,3 a 6,5 (Brasil, 1992) e de cada parcela, 20 escleródios permaneceram imersos em $2 \mathrm{~mL}$ da solução de TCT por $24 \mathrm{~h}$, a $30^{\circ} \mathrm{C}$, em vidros de ensaio recobertos por papel alumínio. Em seguida, os escleródios foram lavados em água destilada, secos em papel-toalha, cortados ao meio e visualizados sob microscópio estereoscópio.

Germinação dos escleródios em meio de cultura: Após 14 a $18 \mathrm{~h}$ dos tratamentos nos coletores, os escleródios recuperados do substrato por peneiramento úmido permaneceram por $72 \mathrm{~h}$ em dessecadores contendo sílica gel até a realização dos testes de viabilidade. Posteriormente, os escleródios foram desinfestados em álcool $70 \%$ e hipoclorito de sódio (NaOCl) $20 \mathrm{~g} \mathrm{~L}^{-1}$, por $30 \mathrm{~s}$ (Punja e Rahe, 1993), lavados por três vezes em água esterilizada e semeados em meio BDA-salino-cloranfenicol (BDASC: composto de BDA-Sigma ${ }^{\circledR}(\mathrm{pH}=5,8), \mathrm{NaCl}$ a $0,08 \%$ e cloranfenicol a 250 ìg $\mathrm{mL}^{-1}$ ), espaçados entre si de $1 \mathrm{~cm}$. Após $72 \mathrm{~h}$ a $30+/-1^{\circ} \mathrm{C}$, avaliou-se a porcentagem de escleródios germinados (presença de hifas) e não-germinados (ausência de hifas) sob microscópio estereoscópio.

\section{RESULTADOS E DISCUSSÃO}

Os dois coletores solares testados foram igualmente eficientes no aquecimento do substrato e na erradicação de escleródios de $S$. rolfsii. No primeiro ensaio do dia 06 de outubro de 2000, a radiação solar global atingida nas horas mais quentes do dia foi de 812 a $749 \mathrm{~W} \mathrm{~m}^{-2}$, entre $10 \mathrm{~h}$ e $13 \mathrm{~h}$, e a temperatura máxima interna do substrato no interior dos canos alcançou $45^{\circ} \mathrm{C}$ (Figura 2). Mesmo o dia estando nublado, os coletores foram eficientes na erradicação de $100 \%$ dos escleródios. Os escleródios tratados não foram capazes de germinar em meio BDASC (Tabela 1). Observou-se, no entanto, $100 \%$ de colonização dos escleródios por bactérias. Não se observou, ainda, diferença entre canos e posições das amostras nos canos quanto à erradicação dos escleródios do patógeno. Os escleródios das testemunhas misturados ao substrato, mas não submetidos ao aquecimento, germinaram em meio de cultura, no mesmo período de incubação (Tabela 1). 


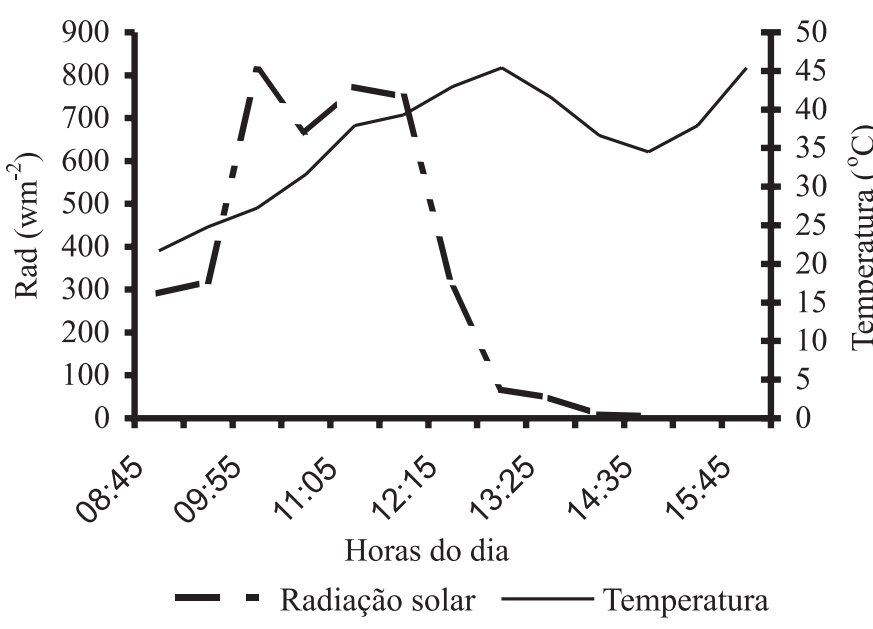

FIGURA 2 - Radiação solar global registrada durante o primeiro ensaio (06/10/2000) e temperaturas registradas no substrato no interior da parte superior do tubo 3 , no coletor de 5 ".

TABELA 1 - Efeito do aquecimento do substrato na erradicação dos escleródios de Sclerotium rolfsii em dois coletores solares, expresso pela porcentagem de escleródios não germinados em BDASC e não-coloridos em TCT.

\begin{tabular}{lcccc}
\hline Ensaios & \multicolumn{2}{c}{$\begin{array}{c}\text { Germinação (BDASC) } \\
{ }^{1} \text { Testemunha/tratamento }\end{array}$} & $\begin{array}{c}\text { Coloração (TCT) } \\
{ }^{2} \text { Testemunha/tratamento }\end{array}$ \\
\hline $1^{\circ}-06 / 10$ & $100 \%$ & 0 & - & - \\
$2^{\circ}-25 / 10$ & $95 \%$ & 0 & $95 \%$ & 0 \\
$3^{\circ}-13 / 12$ & $100 \%$ & 0 & $85 \%$ & 0 \\
\hline
\end{tabular}

${ }^{1 \text { e } 2}$ média de 20 esclerócios $\mathrm{x} 4$ repetições

Nos segundo e terceiro ensaios, efetuados nos dias 25 de outubro e 13 de dezembro de 2000, a radiação solar global às $13 \mathrm{~h}$ foi de 877 e $908 \mathrm{~W} \mathrm{~m}^{-2}$, respectivamente, o que provocou um aquecimento elevado em ambos os coletores (Figuras 3 e 4). Constatou-se, também, que o número de horas com temperaturas do substrato acima de $50^{\circ} \mathrm{C}$ foi de aproximadamente $7 \mathrm{~h}$, em ambos os coletores, nos dois ensaios (Figuras 3 e 4). As temperaturas máximas atingidas pelos coletores nos dois ensaios foram de 60 a $80^{\circ} \mathrm{C}$, o que foi suficiente para erradicar $100 \%$ dos escleródios do patógeno, conforme constatado pela ausência de germinação em BDASC e coloração por TCT (Tabela 1).

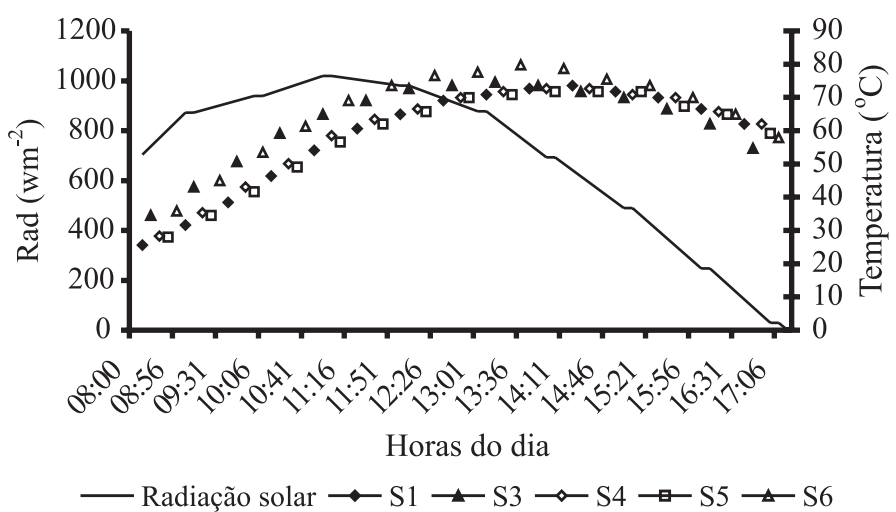

FIGURA 3 - Temperatura do substrato no interior dos coletores de 5 e 6 polegadas e radiação solar global, em 25/10/2000. Temperaturas registradas nos sensores S1 e S3 (para posições inferiores e superiores, respectivamente, do tubo 3 do coletor de 5 polegadas) e ns sensores S4, S5 e S6 (posições superiores, medianas e inferiores, respectivamente, do tubo 3 , do coletor de 6 polegadas).

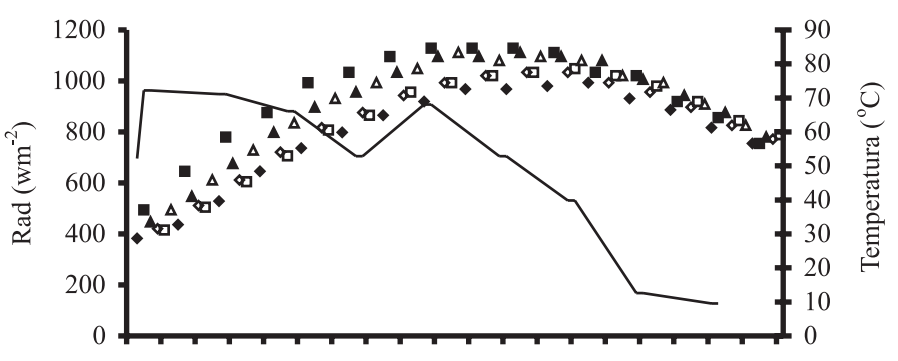

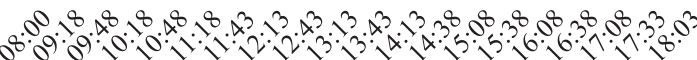

Horas do dia

$\longrightarrow$ Radiação solar $\rightarrow \mathrm{S} 1 \rightarrow-\mathrm{S} 2 \rightarrow \mathrm{S} 3 \rightarrow \mathrm{S} 4 \rightarrow \mathrm{S} 5 \rightarrow \mathrm{S} 6$

FIGURA 4 - Temperaturas do substrato no interior dos coletores de 5 e 6 polegadas e radiação solar global, em 13/12/2000. Temperaturas registradas nos sensores $\mathrm{S} 1, \mathrm{~S} 2$ e S3 (tubo 2, 3 e 4 , respectivamente, na posição mediana do coletor de 5 polegadas) e nos sensores S4, S5 e S6 (tubo 2, 3 e 4, respectivamente, na posição mediana do coletor de 6 polegadas), respectivamente.

Não houve diferença entre os dois coletores, entre posições dos canos e posições das amostras dentro dos canos, bem como entre os dois substratos quanto ao aquecimento e quanto à eficiência de erradicação do patógeno. Os escleródios não-tratados apresentaram 95 e $100 \%$ de escleródios germinados em meio de BDASC e, 95 e $85 \%$ de escleródios coloridos por TCT, nos segundo e terceiro ensaios, respectivamente (Tabela 1 ).

Apesar das altas temperaturas atingidas dentro dos canos dos coletores solares, pôde-se observar que não houve esterilização do substrato, em vista do crescimento de bactérias nos escleródios em meio de cultura.

Observou-se, no primeiro ensaio, que apesar da temperatura máxima atingida durante o período de tratamento ter sido baixa $\left(45^{\circ} \mathrm{C}\right), \mathrm{o}$ tempo de exposição a essa temperatura foi relevante no enfraquecimento dos escleródios de S. rolfsii. Segundo Lifshitz et al. (1983), o aquecimento subletal enfraquece os escleródios, tornando-os vulneráveis à contaminação por bactérias antagonistas. Os autores observaram que o aquecimento prolongado pode causar rachaduras na superfície externa dos escleródios, possibilitando o vazamento de conteúdo celular para o meio e facilitando o crescimento bacteriano (Lifshitz et al., 1983). Exemplos análogos com outros patógenos demonstraram os efeitos de temperaturas subletais na redução da capacidade infectiva e na viabilidade de inóculos (Freeman e Katan, 1988; Tjamos e Fravel, 1995).

Em experimentos de solarização do solo, o número de horas acumuladas tem papel fundamental na erradicação de escleródios de $S$. rolfsii, como demonstrado por Malathrakis e Loulakis (1989) e Ristaino et al. (1996). Apesar da baixa temperatura atingida pelos coletores solares no primeiro ensaio, o período de um dia foi suficiente para erradicar os escleródios do patógeno submetidos ao aquecimento. Na solarização do solo, foram necessários de 40 a 60 dias, para a erradicação de $S$. rolfsii à temperatura do solo de $42^{\circ} \mathrm{C}$ (Malathrakis e Loulakis, 1989). Talvez, em vista da energia absorvida pelos coletores solares não se dissipar facilmente para o ambiente, não seja necessário mais que um dia de tratamento, como ocorre com a solarização do solo no campo. A variação de umidade do solo durante o extensivo tempo de tratamento de solarização pode alterar a distribuição do calor no solo, o que talvez não aconteça nos coletores solares. Por outro lado, poderia haver outros efeitos não térmicos (Stapleton et al., 1985) envolvidos na erradicação do fungo. O filme de polietileno é pouco permeável a gases e, assim, ocorre acúmulo de $\mathrm{CO}_{2}$, amônia ou até mesmo de enxofre. A presença desses gases foi relatada no controle de patógenos de solo (Katan, 1981). 
O coletor solar da EMBRAPA testado na desinfestação de substrato provocou a morte de S. rolfsii em um dia de tratamento (Ghini, 1993). O resultado obtido pelo coletor solar produzido pela UENF confirma o ocorrido com o protótipo pioneiro. Constatou-se que as temperaturas alcançadas pelos coletores solares nos dois últimos ensaios ultrapassaram aquelas exigidas para a morte dos escleródios de $S$. rolfsii, que é de $52^{\circ} \mathrm{C} / 30$ min em ensaio in vitro (Martins, 2001).

O umedecimento dos substratos até sua capacidade de campo em ensaio in vitro pode melhorar a condução de calor e favorecer a erradicação dos escleródios de S. rolfsii (Martins, 2001). Porém, os coletores solares podem não perder eficiência na erradicação do patógeno e apresentarem resultados semelhantes, com substratos umedecidos a teores de umidade abaixo aos da capacidade de campo.

Martins (2001), em estudos in vitro, obteve boa correlação entre germinação e coloração dos escleródios pelo TCT. Neste trabalho, a ausência de coloração no teste de TCT confirmou a inativação dos escleródios tratados nos coletores. A falta de coloração vermelha dos escleródios indica que houve desnaturação protéica e inibição da atividade de desidrogenases.

Os coletores solares testados nas presentes condições foram eficientes na erradicação dos escleródios de $S$. rolfsii. Porém, os coletores ainda necessitam ser testados para outros patógenos de solo de importância econômica para a região, os quais podem ser mais tolerantes ao calor, como Fusarium spp. (Freeman et al., 1989), por exemplo. Há, também, necessidade de se testar o efeito do aquecimento contra microorganismos benéficos, antagonistas de fitopatógenos e simbiontes de plantas, como os fungos micorrizos e Rhizobium. Necessita-se, ainda, investigar a eficiência dos coletores testados em diferentes épocas do ano, condições de clima e substratos, para expandir a utilização do aparelho. E, finalmente, avaliar precisamente as alterações dos constituintes químicos de substratos, após o aquecimento nos coletores solares, visto que durante a solarização do solo ou pelo tratamento a vapor, ocorrem mudanças na disponibilidade de elementos minerais do solo (Chen e Katan, 1980; Katan, 1981; Stapleton et al., 1985).

\section{CONCLUSÕES}

Os dois coletores utilizados foram igualmente eficientes na erradicação de $S$. rolfsii, nos três ensaios efetuados. Para isto, recomenda-se utilizá-los preferencialmente em dias ensolarados, iniciando-se o tratamento pela manhã a partir das $8 \mathrm{~h}$, prosseguindo-se até às $16 \mathrm{~h}$.

\section{REFERÊNCIAS BIBLIOGRÁFICAS}

ALBREGTS, E.E.; GILREATH, J.P.; CHANDLER, C.K. Soil Solarization and Fumigant Alternatives to Bromide for Strawberry Fruit Production. Soil and Crop Science Society of Florida Proceedings, Brandentin, v. 55, p. 16-20, 1996.

BRASIL. MINISTÉRIO DAAGRICULTURAE DOABASTECIMENTO.

Regras para análise de sementes. Brasília, 1992.365p.

BEDENDO, I.P. Damping off. In: FILHO, A. B.; KIMATI, H.; AMORIM,
L. (Ed.) Manual de fitopatologia : princípios e conceitos. São Paulo: 1995. p. 820-828.

CHEN, Y.; KATAN, J. Effect of solar heating of soils by transparent polyethylene mulching on their chemical properties. Soil Science, Baltimore, v.103, p.271-277, 1980.

FREEMAN, S.; KATAN, J. Weakening effect on propagules of Fusarium by sublethal heating. Phytopathology, St. Paul, v.78, p.1656-1661, 1988.

FREEMAN, S.; GINZBURG, C.; KATAN, J. Heat shock protein synthesis in propagules of Fusarium oxysporum f.sp. niveum. Phytopathology, St. Paul, v.79, p.1054-1058, 1989.

GHINI, R. Energia solar pode controlar doenças de plantas. A Lavoura, Rio de Janeiro, p.14-15, Mar/Abr, 1991.

GHINI, R.; BETTIOL, W. Coletor Solar para desinfestação de substratos. Summa Phytopathologica, Jaboticabal, v.17, p. 281-287, 1991.

GHINI, R. A solar collector for soil Disinfestations. Netherland Journal of Plant Pathology, Washington, v.99, p.45-50, 1993.

KATAN, J. Solar pasteurization of soils for disease control: status and prospects. Plant Disease, St. Paul, v.64, p.450-454, 1980.

KATAN, J. Solar heating (solarization) of soil for control of soilborne pests. Annual Review of Phytopathology, Palo Alto, v.19, p.211-236, 1981.

LIFSHITZ, R.; TABACHNIK, M.; KATAN, J.; CHET, I. The effect of sublethal heating on sclerotia of $S$. rolfsii. Canadian Journal of Microbiology, Ottawa, v.29, p.1607-1610, 1983.

MALATHRAKIS, N.E.; LOULAKIS, M.D. Effectiveness of the type of polyethylene sheet on soil solarization. Acta Horticulturae, Washington, v.255, p.235-239, 1989.

MARTINS, M.V.V. Erradicação in vitro de escleródios de Sclerotium rolfsii a diferentes temperaturas e umidades do substrato e em coletores solares, 1998. 45f. Dissertação (Mestrado em Produção Vegetal) - Universidade Estadual do Norte Fluminense, Campos dos Goytacazes, 2001.

PUNJA, Z.K.; GROGAN, R.G. Eruptive Germination of Sclerotia of $S$. rolfsii. Phytopathology, St. Paul, v.71, p.1092-1099, 1981.

PUNJA, Z.K. The Biology, Ecology and Control of S. rolfsii. Annual Review of Phytopathology, Palo Alto, v.23, p.97-127, 1985.

PUNJA, Z.K.; RAHE, J.E. Sclerotium. In: SINGLETON, L.L; MIHAIL, J.D; RUSH, C.M. (Ed.) Methods for research on soilborne phytopathogenic fungi. St. Paul, Minnesota, 1993. p.166-170.

RISTAINO, J.B.; PERRY, K.B.; LUMSDEN, R. D. Soil Solarization and Gliocladium virens Reduce the Incidence of Southern Blight $(S$. rolfsii) in Bell Pepper in the Field. Biocontrol Science and Technology, Abingdon, v.6, p.583-593, 1996.

STAPLETON, J.J.; QUICK, J.; DeVAY, J.E. Soil Solarization: effects on soil properties, crop fertilization and plant growth. Soil Biology and Biochemistry, Mandan, v.17, p.369-373, 1985.

TJAMOS, E.C.; FRAVEL, D.R. Detrimental effects of sublethal heating and Talaromyces flavus on microsclerotia of Verticillium dahliae. Phytopathology, St. Paul, v.85, p.338-392, 1995. 